\title{
Impact of Sustainable Study Abroad Course on Students
}

\section{Prof. Patricia Fox, Indiana University-Purdue University of Indianapolis}

Professor Patricia Fox is a Clinical Assistant Professor in the Department of Technology Leadership and Communication in the Purdue School of Engineering and Technology at Indiana University-Purdue University Indianapolis (IUPUI). Pat has been a member of the faculty for over 35 years. She has previously served as Associate Chair and Associate Dean in the School. Pat teaches leadership, ethics, sustainability, and study abroad courses. She has held a number of leadership roles in the American Society for Engineering Education (ASEE) including four terms on the ASEE Board as well as serving two times as the Chair of Engineering Technology Council. Pat is a Fellow of ASEE. Her research interests include sustainability and study abroad education.

\section{Dr. Charles McIntyre, Indiana University-Purdue University of Indianapolis}

Charles McIntyre is a Professor and Program Director of the Construction Engineering Management Technology Program at Indiana University Purdue University Indianapolis (IUPUI). He received a Ph.D. from Penn State in 1996. Prior to joining IUPUI, he was a faculty member and former chair in the Department of Construction Management and Engineering at North Dakota State University in Fargo. Dr. McIntyre's current research includes sustainable construction, green building, and industry-academic collaborations. He is an active member of the American Society for Engineering Education and the American Council for Construction Education. Dr. McIntyre has served on the ASEE Board of Directors and is an ASEE Fellow.

\section{Dr. Brandon Sorge, Indiana University-Purdue University of Indianapolis}

Brandon Sorge is an Assistant Professor of STEM Education Research in the Department of Technology Leadership and Communication at the Purdue School of Engineering and Technology at IUPUI. His research interests include all aspects of STEM education, especially the impacts of all levels of policy on the development of a STEM literate workforce. He also conducts research related to leadership and the role of corporate responsibility in employee recruitment and retention. Before coming to IUPUI, Brandon ran the day-to-day operations of the Indiana STEM Resource Network where he co-founded the Indiana Science Initiative which provides research based science materials and professional development to approximately 2200 teachers impacting over 50,000 students each year. . 


\title{
Impact of Sustainability Study Abroad Course on Students
}

\begin{abstract}
The School of Engineering and Technology at Indiana University Purdue University Indianapolis (IUPUI) has offered a short study abroad course, called GO GREEN, on sustainable practices in businesses, industries and municipalities in Germany for the past 15 years. Over 150 students have participated in the course since its inception in 2003. A survey was conducted to determine what these students had ascertained from the course and to see if any of these students were using the skills acquired in this class in their work or daily lives. The survey, consisting of 23 questions, was designed to determine how students have used the interdisciplinary subject matter of sustainability in their lives and careers after taking the course, as well as, questions about key elements of the course. Some of the results of the survey will be discussed in this paper/presentation.
\end{abstract}

\section{Importance of Sustainability}

Ray Anderson was known as an industrial engineer and radical industrialist and America's Greenest CEO [1]. He defined sustainability as "survival" - survival for his company, for this nation, and even for our species [1]. In 1994, Anderson began transforming his petroleum intense modular tile carpet company, Interface, Inc., from the "take-waste-make business model" into an organization with a goal of a zero-environmental footprint, set for 2020 [1]. The Interface Inc. journey and success is proof that any corporation can truly work towards a zero-environmental footprint, be competitive, lead the industry, and make a profit. In fact, according to Anderson, companies can lead the way towards sustainability [1].

Sustainability is an important interdisciplinary topic for any student, especially those studying engineering and technology. The National Academy for Engineering (NAE) in 2008 along with an international group of technological leaders developed the Grand Challenges for Engineering, which includes sustainable or sustainability related challenges, such as, making solar energy more economical, restoring and improving urban infrastructure, providing access to clean water, and developing carbon sequestration methods [2]. There are many other international groups that have identified Global Challenges for the $21^{\text {st }}$ Century [3] many of which address sustainability and sustainable development specifically. Therefore, it is important for students to understand what sustainability is and how it can relate to their career. The American Society for Engineering Education (ASEE) also supports sustainability education, "ASEE believes that engineering graduates must be prepared by their education to use sustainable engineering techniques in the practice of their profession and to take leadership roles in facilitating sustainable development in their communities [4]." 


\section{Germany and Sustainability}

Germany formally incorporated the principle of sustainability into their national policies in 2002 . However, the country has been practicing sustainability for over 300 years starting with their forest management practices [5]. Germany has taken the lead as a nation on sustainable issues, especially over the past half a century. The results have been impressive in sustainable urban structures and planning, renewable energy usage, sustainable transportation systems, and green policies at the local, state and national levels [6]. All of these sustainable efforts have led to economic growth and innovation within Germany [6]. The German's have instituted laws to promote a more environmentally sustainable country, the product of decades of work to transform their country into a "green" energy, urban and transportation model. Germany has prospered under this sustainable plan and maintained growth, even after the recession in 2008, emerging with a strong economy [6]. The German government's current sustainable development strategy plan is based on a long term holistic, integrated approach with viable solutions that can only be achieved if interdependencies are managed [5].

Germany continuously works towards improving its green environment. First, by eliminating nuclear power in the country. In 2011, there were 17 nuclear power plants in operation. By 2022 the last plant will be closed. The power gap created is being filled with renewables, gas turbines and conservation [7]. The generation of renewable energies compared to gross energy consumption in 2015 was approximately $15 \%$, the target for 2020 is $18 \%$ [8]. Germany's target for 2030 is $30 \%$, and $60 \%$ for 2050 [8]. In 2014, the German's updated the Germany Renewable Energy Act (EEG), which is the backbone behind the Energiewende (a law that gives renewables priority on the grid and ensure the investors receive compensation despite the price of electricity) [7]. Another unique idea Germans have is charging for bad behavior. One example is the German tax on petroleum, "eco-tax" which is used to lower payroll taxes and makes German workers more competitive internationally [7]. Germans tend to waste very little, therefore, due to the Cogeneration Act of 2002, 25\% of the country's power supply will come from Cogeneration by 2020 [7]. Cogeneration is heat that is recovered from power and used as an energy source. The Germans consider Cogeneration a renewable source of energy. Since $40 \%$ of energy is lost in buildings, the German Renewable Heat Act is aimed at increasing renewable sources in buildings to $14 \%$ by 2020 [7]. Conserving energy is another aspect of the German plan to be green and sustainable. Renovating buildings to fulfill Passive House standards is one of Germany's biggest endeavors. In addition, designing with eco-friendly products and highperformance standards for energy are at the top of Germany's list. Another important topic for Germans is alternative forms of transportation. Germany has extensive public transportation system and bike networks. In addition, $88 \%$ of the population lives near a bus or train stop [7]. Last, but not least, Germans are experts in recycling, however, there is a greater call in Germany for increased optimization to an already sophisticated and elaborate recycling system [7]. Germans have taken the steps necessary to live in a green and sustainable environment because they value that life style and they fully understand climate change issues.

Unfortunately, the U.S., as a whole, is not moving in the same directions as Germany. However, some cities in the U.S. are actively pursuing sustainable agendas. Portland, Oregon leads the list for the most sustainable city in the U.S. with half of its energy coming from renewable sources [9]. Other U.S. cities are leading the way with large scale recycling and composting programs. 
San Francisco, eliminates $80 \%$ of the city's waste through its recycling and composting program. In addition, the city has approximately 700 LEED-certified building projects [9]. In order to have a greater and long-lasting impact, sustainability issues need to be addressed at the national, state, and local level, like in Germany. At the corporate level, companies such as Interface, Inc. have made tremendous contributions to the movement of sustainability in the U.S.

\section{Study Abroad Course About Sustainability}

Since 2003, the Department of Technology Leadership and Communication at the Indiana University Purdue University Indianapolis (IUPUI) has offered GO GREEN, a study abroad course, which stands for Green Organizations: Global Responsibility for Environmental and Economic Necessity. This course was originally designed for engineering and technology students to study real world application of sustainable practices in businesses, industries and municipalities and German culture. This 400-level course counts towards an elective or technical elective for several engineering and technology departments in the school. The majority of the students who participate in GO GREEN are majors in the School of Engineering and Technology. From 2003 to 2017 (109 of 152) 72\% of students enrolled in GO GREEN were majors in the School of Engineering and Technology, the remainder were from other departments in the university (28\%). The GO GREEN course is a one-week or 8-day study abroad course taught partially in Mannheim, Germany where students experience first-hand realworld applications of sustainability. The course includes approximately 30 hours of classroom instruction and discussion where students are introduced to the subjects (sustainability and German culture) and travel related matters prior to the overseas portion of their trip. After returning from Germany, students meet for half a day to discuss and reflect on their learning experiences abroad. The overseas component of the course was designed so that working students could participate in a study abroad program. The GO GREEN program was specifically designed to be approximately one week abroad and at a low cost so that working students could afford the program and have time to attend. The average cost for the program, not including tuition and fees, is approximately $\$ 2,500$. The classes at the university are held on Saturdays to avoid conflicts with other classes or normal work schedules. In Germany, students visit, tour and receive lectures on sustainable practices at German companies, such as, Daimler (Mercedes), MVV Energie, Roche and Volkswagen. Other examples include visits to the University of Kaiserslautern to see a Passive Haus. Talks on energy policies about the State of Rhineland Palatinate. In addition, students visit the city of Freiburg to learn about their green history and visit the sustainable village of Vauban. These are the types of experiences the GO GREEN study abroad students encounter during their week in Germany. During this week abroad, students are housed in Mannheim but travel to many other cities during the week depending on the scheduled visits; such as Freiburg, Ladenburg, Koln, Frankfurt, Heidelberg, Speyer, and Kaiserslautern.

Upon completion of the GO GREEN course students are be able to: demonstrate knowledge of issues in sustainability as it relates to businesses, industries, and municipalities nationally and internationally; demonstrate knowledge and appreciation of German culture with some language skills; analyze and evaluate sustainable content from course to apply in work and life; and demonstrate the interconnectivity of global concerns. GO GREEN students also learn responsibility and independence. Each student is responsible for purchasing their own airline tickets to Frankfort and public transportation to Mannheim. Students also arrange their own 
accommodations in Manheim. The majority of the students in the course have never traveled outside of the U.S. and some have never flown. Faculty explain and assist students through a series of meetings on campus prior to leaving the country and encourage students to fly and house together. This method has not created any major issues since the course's inception, however, it has enabled students to learn to be independent and confident in their international travelling skills. Many students travel to other German and European cities after completing the study abroad component of the GO GREEN course.

\section{Method}

A sequential mixed-methods research approach was utilized in this project [10]. Student quotes were collected via class documents, while quantitative data were collected using an online survey. The IUPUI alumni database was used to obtain emails of the previous GO GREEN attendees for the survey. However, not all the emails were valid. The survey consists of 23 questions designed to determine how students have used the interdisciplinary subject matter of sustainability in their lives and careers after taking the course, as well as, questions about key elements of the course. A mix of open-ended and closed-ended questions were used. The survey was administered using the online survey tool Qualtrics and IRB approval was granted by the local institution.

Survey questions primarily related to course improvement and to student learning. Additional qualitative data were obtained from GO GREEN student documents to provide support to the survey findings. Specifically, these qualitative data were collected from GO GREEN required course papers. For the course, students are required to write a short three to five-page paper on the German culture describing, documenting, and reflecting on the student's reactions to German aspects of behavior, attitudes, and customs, as well as the similarities and differences of Germans vs American citizens. In addition, students write an in-depth comparison analysis paper (eight to ten pages) of at least two industries or places visited in Germany. The industry or place are compared with one in the U.S. The first part of the paper is an introduction to the subject of sustainability and globalization. How does globalization play into sustainability? Why is it important to address sustainability globally? The next two parts should contain information about the German company, industry, municipality and the similar company, industry, or municipality in U.S, looking at the sustainable issues, similarities and differences. The final part integrates learning from the site visits, course readings, and addresses the following questions: how the readings, lectures, site visits relate to the student's understanding of sustainability; and how the student's role as a customer, citizen, or manager today, tomorrow or in the near future will affect decision-making in companies, communities, countries, and globally due to their experiences in the class.

\section{Results}

Just under $29 \%$ (44) of the students responded to the survey, including partial responses. Of the respondents, 24 were male and 20 were female. Forty-two live in the United States and two live in Europe. The respondents had diverse occupations listed varying from engineer, student, furniture maker, project manager, program manager, interior designer, airline pilot, human resource professional, to name a few. 
The survey asked if the GO GREEN study abroad program impacted respondents' daily lives. Table 1 indicates that $88 \%$ of the respondents were positively impacted by the course. GO GREEN respondents were asked how did their daily sustainable practices change as a result of the course. Their answers from the survey included: "started recycling; more cognizant of different companies and their "green" practices/products; more thoughtful intentions of my own sustainable practices; after witnessing 60-80 year olds bicycling and commuting in Germany I started commuting by bicycling to work; conscious of energy usage and where it comes from; more aware of cultural differences and how entitled we are to technology, consumption and waste; minimize consumption of embodied energies from food, electricity usage and building envelopes, etc.; drive plug-in hybrid car; take the "less is more" attitude - eat organically and use less packaging; active in local community to be all green; composting practices; and eliminate personal waste."

Table 1- Impact of Daily Sustainable Practices

\begin{tabular}{|c|c|c|}
\hline \multicolumn{3}{|c|}{$\begin{array}{c}\text { Did the Go Green Trip impact your daily sustainability } \\
\text { practices? }\end{array}$} \\
\hline & Frequency & Percent \\
\hline Yes & 37 & $88 \%$ \\
\hline No & 5 & $12 \%$ \\
\hline Total & 42 & $100 \%$ \\
\hline
\end{tabular}

GO GREEN students were asked what knowledge and skills regarding sustainability have you applied in your current job. Survey responses include the following: "reducing energy use and cost; life cycle assessment; reuse of furniture instead of purchasing new; material selection and usage; recycling water consumption/preservation practices; recycling and waste management; fuel savings; reuse of surplus; energy consumption; cultural differences; solar panel installation and usage; and reducing material in aircraft modifications design."

As indicated in Table 2, ninety-five percent of the students that responded, either agreed or strongly agreed that they learned about the culture of the host country. Over the years, many GO GREEN students have had a positive response to learning about a new culture. For example, a psychology student in 2009 said, "My experience abroad was nothing short of amazing. I was able to polish up my broken German, expand my cultural boundaries, and relate how I live going green. I met so many wonderful people and had the chance to hear their stories. I learned so much professionally, ecologically, and personally. This opportunity was definitely a once in a lifetime experience that I would not trade for anything [11]." With regards to culture, one mechanical engineering student said in 2011, "It is important for everyone to get out of their comfort zones occasionally and open their eyes to other cultures. From observing, learning, and compiling my own experiences and interactions with the German culture I was able to increase my respect for their beliefs and values. Differences in culture can appear at work, school, or in my personal life. This learning experience allowed me to practice dealing with these encounters. No matter what career field I choose to pursue I will have to be able to work and function with many different people from all different backgrounds and cultures. I am appreciative of the knowledge I've gained from studying abroad in Germany [12]." 
Table 2 - Cultural Learning

\begin{tabular}{|c|c|c|}
\hline \multicolumn{3}{|c|}{ While abroad I learned about the culture of the host country. } \\
\hline & Frequency & Percent \\
\hline Strongly Agree & 29 & $67 \%$ \\
\hline Agree & 12 & $28 \%$ \\
\hline Undecided & 2 & $5 \%$ \\
\hline Disagree & 0 & 0 \\
\hline Total & 43 & $100 \%$ \\
\hline
\end{tabular}

One survey question asked to what extent the students interacted with the local population of the host county? As shown in Table 3, a large number, $73 \%$, interacted a great deal or a lot and 28\% interacted a moderate amount, which is consistent with the results Table 2 concerning cultural learning.

Table 3 - Interaction with local population

\begin{tabular}{|c|c|c|}
\hline \multicolumn{3}{|c|}{ How much did you interact the local population of the host country? } \\
\hline & Frequency & Percent \\
\hline A great deal & 16 & $40 \%$ \\
\hline A lot & 13 & $33 \%$ \\
\hline A moderate amount & 11 & $28 \%$ \\
\hline Total & 40 & $100 \%$ \\
\hline
\end{tabular}

A large majority of the respondents (77\%) agreed or strongly agreed that the GO GREEN study abroad trip helped them develop an appreciation for learning new languages, as indicated in Table 4. It should be noted that for the course, students did not need to know the German language, however, students were taught some basic words and phrases and were encouraged to use free language apps.

Students often mimicked this response, as one interior design student from summer of 2003 said, "The language difference originally was concerning, but after arriving I found that most people could speak English without much difficulty making it easy to communicate. Another pleasant surprise was the friendliness of the German people, who on more than one occasion, went beyond the norm to be helpful and accommodating. Just as things became more familiar and similar they also remained different, adding to the enjoyment of the trip. The lessons learned in Germany went beyond the expected [13]."

Table 4 - Language Appreciation

\begin{tabular}{|c|c|c|}
\hline \multicolumn{3}{|c|}{ GO GREEN helped me develop an appreciation for learning new languages. } \\
\hline & Frequency & Percent \\
\hline Strongly Agree & 22 & $51 \%$ \\
\hline Agree & 11 & $26 \%$ \\
\hline Undecided & 6 & $14 \%$ \\
\hline Disagree & 4 & $9 \%$ \\
\hline Total & 43 & $100 \%$ \\
\hline
\end{tabular}


Another question in the survey asked if the GO GREEN study abroad trip sparked student interest in pursuing a career in sustainability. Forty-two percent agree or strongly agree, $30 \%$ were undecided, and $28 \%$ disagreed with the statement, as documented in Table 4 . This is interesting because most of the students who attended the GO GREEN course were generally, either junior or senior level. The $42 \%$ indicates that there may be an interest in the subject matter of sustainability even though the only sustainability program at the university is offered by the School Public and Environmental Affairs in policy. Of the 152 students that have taken the GO GREEN course over the span of 15 years, only 6 students have been SPEA majors.

Table 5 - Career in Sustainability

\begin{tabular}{|c|c|c|}
\hline \multicolumn{2}{|c|}{ GO GREEN sparked my interest in pursuing a career in sustainability. } \\
\hline & Frequency & Percent \\
\hline Strongly Agree & 8 & $19 \%$ \\
\hline Agree & 10 & $23 \%$ \\
\hline Undecided & 13 & $30 \%$ \\
\hline Disagree & 12 & $28 \%$ \\
\hline Total & 43 & $100 \%$ \\
\hline
\end{tabular}

A majority of the students that participated indicated that they were amazed and changed by the study abroad experience. Faculty have collected comments from all students since the course started. The themes have been consistent and generally have the same reaction as this mechanical engineering student in 2011, "In summary, this trip was extraordinarily eye opening for me in many different ways. I am SO glad that I had the opportunity to travel abroad and to experience a different culture. Germany is even somewhat similar to the U.S. as far as development, I can't even begin to imagine going to a country where you can't speak the language - and it's underdeveloped where people don't speak English, and can barely read or write in their own language. I gained so much out of this experience; I hope that I never forget the details. I kept a detailed journal of day to day observations, but reading back through itsome of it is already starting to fade out of memory. My biggest hope is that I never forget to appreciate the bilingual signs, to never be rude or impatient with someone who doesn't speak English as well as I do. I hope I'll always remember that first 20-30 minutes of being in country, and the feeling of complete vulnerability and being lost. It was an amazing experience and I would encourage everyone to travel abroad at least once in their life [14]."

GO GREEN students were also asked what was the "biggest take away" from the GO GREEN study abroad course. Answers from the survey included: "you can build a home that makes more energy that it consumes; knowledge of the companies that we visited; the U.S. is $50+$ years behind sustainable practices in Europe; Germany is very beautiful and it didn't happen by accident; looks great on a resume; my time and experiences abroad; cultural differences and my free time abroad; there are many but the one that stuck with me the most is that companies have the power to change and there are truly business cases for it; the application for sustainability and its application in nearly every aspect of life; the opportunity to visit a new country was the most valuable takeaway, I never had been outside of North America prior to this trip, it instilled in me a great fondness for traveling and made me want to both travel more and also to try to implement sustainable practices wherever possible now that I know they are in use in other places; presumably growth and cultural understanding; new understanding of environmental practices; 
the experience was enriching personally and educationally, I'm more conscience of the environment related to recycling; honestly everything; being green is both very global and very personal; the U.S has a lot more to do."

Survey respondents were asked to overall rate their experience from excellent to terrible. Table 6 indicates that 36 out of 39 responded to the question answered excellent, while 3 answered good.

Table 6 - Overall Experience

\begin{tabular}{|c|c|c|}
\hline \multicolumn{3}{|c|}{ Rate Overall GO GREEN Experience } \\
\hline & Frequency & Percent \\
\hline Excellent & 36 & $92 \%$ \\
\hline Good & 3 & $8 \%$ \\
\hline Average & 0 & $0 \%$ \\
\hline Poor & 0 & $0 \%$ \\
\hline Terrible & 0 & $0 \%$ \\
\hline Total & 39 & $100 \%$ \\
\hline
\end{tabular}

\section{Conclusions and Recommendations}

Overall, the results of the survey indicate that even a short-term study abroad experience can have some impact on student learning and perceptions. There were clear indicators that an increase in cultural appreciation, foreign language appreciation, and an interest in sustainability were realized by the students that responded to the survey.

Course instructors received numerous quotes from students that suggest this short study abroad program related to sustainability has made huge impact on their thinking. The comments in the survey about what participants are doing in their work and life today are also an indication that the program has made an impact in some of the participant's thinking with regards to sustainable practices.

In the past, this type of student feedback has been used to develop funding proposals for GO GREEN. In fact, course instructors have received several DAAD Grants (Deutscher Akademischer Austauschdienst). The results of this research will be used to develop both internal and external grant proposals.

The authors have concluded that a future study with additional questions to determine if career changes occurred due specifically to the GO GREEN experience and many others need to be addressed. In addition, the authors will seek data from students who did not have a great experience and learn more about its impact on them. A pre- and post-survey will be conducted on future GO GREEN students, with the objective being to determine if student expectations, perceptions, and anticipated learning changed upon completion of the GO GREEN course. Future research will be conducted to locate all 152 course participants and develop a more extensive survey to address topics and issues not included in the survey used in this research. 


\section{References}

[1] R. Anderson, Business Lessons from a Radial Industrialist. St. Martin Griffin, 2010.

[2] NAE, 14 Grand Challenges for Engineering. [Accessed January 2018].

[3] Global Challenges for Humanity, "The Millennium Project: Global Future Studies Research", 2009, http://107.22.164.43/millennium/challeng.html, [Accessed January 2018].

[4] ASEE, "ASEE Statement on Sustainable Development," 1999, https://www.asee.org/about-us/the-organization/our-board-of-directors/asee-board-ofdirectors-statements/sustainable-development-education, [Accessed Jan 2018].

[5] German Sustainability Development Strategy, 2016 version, adopted by the Federal Government on 11 January 2017, http://www.minsk.diplo.de/contentblob/5063918/Daten/7599968/Deutsche Nachhaltigke itsstrategie ru.pdf, [Accessed March 2018]

[6] R. Buehler, A. Jungjohann, M. Keeley, M. and M. Mehing, "How Germany Became Europe's Green Leader: A Look at Four Decades of Sustainable Policymaking," Solutions, 2011, Vol 2, Issue 5.

[7] N. Stewart, "Green Germany: 10 Things Germany is Doing for The Environment," Young Germany, http://www.young-germany.de/topic/live/green-germany-10-thingsgermany-is-doing-for-the-environment, [Accessed January 2018].

[8] Sustainable Development in Germany Indicator Report 2016, Federal Statistical Office of Germany, February 2017, https://www.destatis.de/EN/Publications/Specialized/EnvironmentalEconomicAccountin g/Sustainability/Indicators2016.pdf? blob=publicationFile,[Accessed March 2018].

[9] J. Light, "12 Cities Leading the Way in Sustainability", Moyer and Co, January 4, 2013, http://billmoyers.com/content/12-cities-leading-the-way-in-sustainability/, [Accessed January 2018].

[10] Creswell, John W., et al. "Advanced mixed methods research designs." Handbook of mixed methods in social and behavioral research 209 (2003): 240.

[11] Student \#1, “GO GREEN culture paper,” Psychology student - summer 2009.

[12] Student \#2, “GO GREEN culture paper," Mechanical engineering student -summer 2011.

[13] Student \#3, “GO GREEN culture paper,” Interior design student -summer 2003.

[14] Student \#4, “GO GREEN culture paper,” Mechanical engineering student -summer 2011. 